\title{
L'eau, la vie et la mort
}

\author{
F. Klotz \\ C) Springer-Verlag France 2010
}

L'air et l'eau sont les deux éléments fondamentaux de la vie sur la terre. Cette assertion bien banale doit nous amener à prendre du recul.

L'accès à l'eau potable est la pierre angulaire du développement et du progrès en santé publique. Plus du quart de l'humanité n'a pas accès à ce bien trivial pour les occidentaux, inestimable pour ceux qui en sont démunis.

Mais nous sommes en présence d'une matière au double visage. L'eau potable est source de vie, mais l'eau non contrôlée véhicule d'agents pathogènes ou toxiques, est source de maladie et souvent de mort pour les plus faibles et les enfants.

L'assemblée générale des Nations unies avait lancé, en 1981 à Alma Ata, la décennie internationale de l'eau potable. En dix ans, tous les efforts devaient converger vers l'approvisionnement en eau saine de la population mondiale. Trente ans plus tard, les progrès ont été considérables, mais le but n'est pas encore atteint, puisque plus d'un milliard et demi d'êtres humains n'ont pas accès à l'eau potable. Les raisons en sont multiples, englobant l'instabilité sociopolitique de régions en voie de développement, les conséquences des catastrophes naturelles, et le coût des installations d'assainissement et de distribution qui ne peut être supporté par nombre de budgets de pays pauvres.

Toutes les huit secondes, un enfant meurt d'une maladie liée à l'eau ! Chaque année, plus d'un milliard d'enfants de moins de cinq ans présentent une diarrhée aiguë, et on dénombre près de cinq millions de décès dus à ces diarrhées principalement dans les régions défavorisées. Il serait urgent qu'à côté du vaccin contre la poliomyélite, le vaccin oral contre les gastroentérites à rotavirus soit intégré au programme élargi de vaccination dans la prime enfance.

L'accès à l'eau potable supprimerait $30 \%$ des diarrhées aiguës de l'enfant qui sont une cause majeure de mortalité dans ces contrées, juste derrière le paludisme. Colibacilles, salmonelles, shigelles, vibrions cholériques, virus de la poliomyélite ou des hépatites $\mathrm{A}$ et $\mathrm{E}$, rotavirus, kystes de protozoaires, oocystes de coccidies, œufs et larves d'helminthes, etc. pullulent dans ces eaux soumises à la contamination fécale. Toutes ces maladies évitables sont sources d'une morbidité majeure et un frein au développement. Pour l'OMS, « La bonne qualité de l'eau de boisson fait davantage pour la santé publique que n'importe quel vaccin ou médicament! ».

L'eau ne peut être gérée comme une matière première banale. L'assainissement et la distribution en quantité suffisante de l'eau saine sont de plus en plus coûteux et confiés à des sociétés multinationales. La communauté internationale devrait se mobiliser pour que l'accès à ce bien précieux devienne un droit pour l'être humain, quelle que soit sa place dans la société ou dans le monde. C'est ce que demandent de nombreuses organisations non gouvernementales et le Comité international pour le contrat mondial de l'eau.

Ce droit n'est toujours pas acquis. Souhaitons que, dans un avenir proche, le consensus international privilégie et rejoigne une éthique de santé publique donnant la priorité, au-dessus des contingences économiques et financières, à ce véritable droit à la vie qu'est l'accès pour tous à l'eau potable. Cette prise de position humaniste serait une réelle ouverture vers le développement et vers le respect de l'être humain.

\footnotetext{
F. Klotz $(\bowtie)$

e-mail : fklotz2008@yahoo.fr
} 